\title{
The man who used to shrug - one man's lived experience of TBI
}

\author{
R. Stephen Walsh ${ }^{\mathrm{a}, *}$, Lorraine Crawley ${ }^{\mathrm{b}}$, Neil Dagnall ${ }^{\mathrm{a}}$ and Dónal G. Fortune \\ ${ }^{\mathrm{a}}$ Manchester Metropolitan University, Manchester, UK \\ ${ }^{\mathrm{b}}$ Acquired Brain Injury (ABI), Ireland \\ ${ }^{\mathrm{c}}$ University of Limerick, Limerick, Ireland
}

\begin{abstract}
.
BACKGROUND: Stress is common to the experience of TBI. Stressors challenge physical and psychological coping abilities and undermine wellbeing. Brain injury constitutes a specific chronic stressor. An issue that hinders the usefulness of a stressbased approach to brain injury is a lack of semantic clarity attaching to the term stress. A more precise conceptualisation of stress that embraces experienced uncertainty is allostasis.

OBJECTIVE: An emerging body of research, collectively identifiable as 'the social cure' literature, shows that the groups that people belong to can promote adjustment, coping, and well-being amongst individuals confronted with injuries, illnesses, traumas, and stressors. The idea is deceptively simple, yet extraordinarily useful: the sense of self that individuals derive from belonging to social groups plays a key role in determining health and well-being. The objective of this research was to apply a social cure perspective to a consideration of an individual's lived experience of TBI.

METHODS: In a novel application of interpretative phenomenological analysis (IPA) this research has investigated one person's lived experience in a single case study of traumatic brain injury.
\end{abstract}

RESULTS: Paradox, shifting perspectives and self under stress, linked by uncertainty, were the themes identified.

CONCLUSIONS: A relational approach must be key to TBI rehabilitation.

Keywords: IPA, TBI, rehabilitation, phenomenology, brain injury, social cure, relational

\section{Introduction and literature review}

In-depth examination of the single case has a long and fruitful history in cognitive and clinical neuropsychology (McPherson \& Della Sala, 2019). Indeed, discussing memory, Shallice writes that "most of the greatest scientific advances from neuropsychological investigations has come from studies of a single patient, or less frequently, a few similar patients, each treated as individuals" (Shallice 2019, p.1). A key strength of the single case in the current context is that it permits an increased understanding of how an individual with brain injury experiences the world. The

*Address for correspondence: R. Stephen Walsh, Department of Psychology, Manchester Metropolitan University, 53 Bonsall Street, Birley, M156GX, UK. E-mail: r.walsh@mmu.ac.uk. research presented herein demonstrates that uncertainty is the fulcrum on which one survivor's lived experience of traumatic brain injury (TBI) pivots. Once, in his own words, our participant used to be a man who shrugged things off. Now, uncertainty, experienced as a consequence of living with brain injury, has rendered that old shrugging-self eclipsed by a more precarious self. Accordingly, the authors suggest that mitigation of uncertainty should be key to effective rehabilitation following TBI. The primary challenge faced by the researchers in writing this report was to present the reality of uncertainty, as it manifests in the lived experience of our participant, and those around him, in a frame possessing sufficient conceptual rigour. Therefore this paper is guided by the concept of allostasis, specifically the view that coping with stress requires production of 
strategies that can mitigate uncertainty about the future. In employing IPA the authors provide insights into one survivor's attempt to adjust following a severe TBI. The purpose of this paper is, through focusing intensely on one person's lived experience, to produce transferable knowledge that may usefully be applied in both clinical and research contexts.

\subsection{Brain injury}

TBI is a leading cause of death and disability in young adults throughout the world: fifty million people experience a TBI every year, with an estimated yearly cost of \$US400 billion (Maas et al., 2017). TBI may significantly impact a person's social, cognitive, emotional and behavioural functioning, which may hamper a return to previous roles (Hoofien et al., 2001). Issues of identity and mood are key aspects of medium to long-term outcome following injury (Scholten et al., 2016), and are arguably more important to the individual than their functional outcome.

\subsection{Allostasis and allostatic load}

Stress is common to the experience of TBI (e.g., Qureshi et al., 2019). Cannon (1932) was one of the first academics to apply the concept of stress to homeostasis in humans (Romero, Dickens, \& Cyr, 2008). The idea, borrowed from engineering, acknowledges that external pressures affect people. Explicitly, stress-causing agents (stressors) if acute or prolonged, challenge physical and psychological coping abilities and undermine wellbeing. From this perspective, brain injury represents a specific chronic stressor (Walsh, Fortune, Gallagher, \& Muldoon, 2014). Noting this, Walsh et al. (2014) posit that the integrated social identity model of stress (Haslam, 2004) is pertinent to the study of acquired brain injury (ABI). The model emphasises the need for theorists to consider social and contextual factors that traditional approaches often neglect. This is especially true with individualised conditions such as brain injury, where there is a tendency to focus on the person. The integrated social identity model of stress provides an alternative approach by viewing groups as central to the experience and perception of brain injury and resulting stress (Muldoon, Schmid, \& Downes, 2009). This approach is also relevant to understanding related concepts, and explicitly perceived control (Lazarus \& Folkman, 1984). Other integral concepts within the extant stress literature related to $\mathrm{ABI}$, and $\mathrm{ABI}$ rehabilitation, include moving beyond individualism, group memberships, social identities, context, and perceived control.

An issue that hinders the usefulness of a stressbased approach to brain injury is lack of semantic clarity. The term 'stress' requires clarification because the term denotes both the agent that causes the response, and the reaction. Furthermore, over-stimulation of an emergency response results in 'chronic stress', which is associated with stress related disease (Romero, Dickens, \& Cyr, 2008). Thus, in order to use the term stress appropriately, linguistic disambiguation and operationalisation is necessary. In the present study, the authors link stress with lack of certainty. This is because uncertainty is a stressor that undermines the capacity to predict, plan, and behave efficaciously (Hogg, 2007/2016). A more precise conceptualisation of stress that embraces uncertainty is allostasis. Allostatic load is what happens in terms of neuroendocrine, cardiovascular, neuroenergetic, and emotional terms when stress responses have become chronically activated (McEwan, 1998). In the context of TBI, allostatic load describes the situation when brains, organs whose function is to reduce uncertainty, are unable to resolve uncertainty (Peters, McEwan, \& Friston, 2017). Hence, allostasis is an important concept because it recognises that stressed individuals perceive themselves as lacking control (Peters, McEwan, \& Friston, 2017).

Taking things further, brain injury can usefully be understood as a chronic stressor (Walsh, Fortune, Gallagher, \& Muldoon, 2014). Expanding on this point, Walsh et al. (2014) argue that the integrated social identity model of stress (Haslam, 2004) highlights the importance of attending to the social and contextual factors, often neglected in individualised considerations of illness, and can thus usefully be applied to the study of TBI. Not least because the model moves beyond individualistic analyses of stress. The integrated social identity model of stress regards groups as central to the experience and perception of stress (Muldoon, Schmid, \& Downes, 2009). It is also important to consider the issue of perceived control (Lazarus \& Folkman, 1984); Greenaway et al. (2015) have demonstrated that social identity is a significant predictor of perceived control.

\subsection{The social nature of human beings}

In the early twentieth century, Vygotsky and Luria, founding fathers of modern neuropsychology, strove for a unified theory of mind (Cole, Levitin \& Luria, 
2010). In more recent years, a free energy principle has been proposed which attempts to provide a unified brain theory with particular reference to action, perception, and learning. Friston (2010), in a consideration of the free energy principle (i.e. any self-organising system that is in equilibrium with its environment must minimize free energy) argues that the crucial characteristic of biological systems is their capacity to maintain homeostasis in an environment that is perpetually subject to change. Moreover, Friston argues that maintaining homeostasis requires biological agents to minimize the surprise that they experience. Friston (2010) suggests that there are two methods open to agents in order to avoid surprising states (i.e. uncertainty): (1) Change the world by acting upon it; and (2) Change their own internal states.

\subsection{Social identity}

Lieberman (2013) reasons that contemporary science, including psychology, has a blind spot for 'the social'. The self is important because it is 'a superhighway for social influence' (Lieberman, 2013, p.9). One of the most rigorous and successful ways of conceptualising the self is in terms of social identity (Tajfel, 1974), whereby a person's sense of self is understood as a derivative of the groups they belong to, together with the social and value significance that accompanies group membership(s).

The social identity literature links groups and stress (e.g., Muldoon \& Lowe, 2012). Moreover, Haslam, Jetten, Cruwys, Dingle, \& Haslam (2018) have developed the social identity approach into a new psychology of health. This provides a strong theoretical foundation for linking a range of conditions, including stress and brain injury, to the idea of self. The literature also associates groups with uncertainty. Hogg (2007/2016) developed uncertainty identity theory, which derives from the premise that individuals are unsettled and confounded by indeterminate factors, particularly when they do not know how they should behave individually, or towards others. Hogg (2016) claims that uncertainty, because of the impact it has on identity (i.e. 'self' understood from a social identity point of view), makes it difficult for individuals to act efficaciously. Concomitantly, individuals become motivated to reduce self-relevant uncertainty.

One particularly effective way to reduce selfrelated uncertainty is through social categorisation. The reason for this is that social categorisation provides individuals with prototypes that offer templates as to how they, and others, should behave. Prototypes based on social categorisation allow individuals to know how they should feel. Consequently, the more uncertain that one is about oneself, the more one will strive to belong to groups (Hogg, 2014).

Wilson, Gracey, Evans, and Bateman (2009) give powerful, coherent, and persuasive voice to a clinical acknowledgement of the necessity to engage with the biological, psychological, and social aspects of rehabilitation following TBI. Emotional and identity adjustment are key to rehabilitation and, given the understanding of identity set forth in preceding paragraphs, it seems (to borrow from and paraphrase Baddeley, 1993) that a rehabilitation approach that lacks a relational aspect is akin to a vehicle without an engine because rehabilitation is about the 'bio', the 'psycho' and the 'social'.

\subsection{Interpretative phenomenological analysis (IPA)}

IPA has a focus on the detailed examination of human lived experience (Smith, Flowers, \& Larkin, 2009). As a psychological approach, IPA is underpinned by three key areas in the philosophy of knowledge: phenomenology, hermeneutics, and idiography.

\subsubsection{Phenomenology}

Maurice Merleau-Ponty, a phenomenological philosopher, was much taken with the usefulness of applying an understanding of human nature as embodied. Crucially, for those interested in TBI and rehabilitation, Merleau-Ponty was also much taken with the idea of the intrinsically social nature of human existence. In essence, Merleau-Ponty concluded that human beings cannot exist without others (Bakewell, 2016). 'Phenomenology helps physicians. It makes it possible to consider medical symptoms as they are experienced by the patient rather than exclusively as a physical process' (Bakewell, 2016, p.42). IPA is likely the most common contemporary approach to phenomenological psychology in the UK (Langdridge, 2007).

Phenomenology is a philosophical approach whose focus is on lived experience. Intentionality is a key idea for those who would harness a phenomenological approach for the purpose of psychological analysis. Intentionality is the idea that when we are conscious, there is always something that is the object of our consciousness. A thing that we are "conscious 
of'. To the perceiver, consciousness, and the object of consciousness, are one (Bakewell, 2016).

\subsubsection{Hermeneutics}

Hermeneutics is the theory of interpretation and a consideration of hermeneutics highlights the iterative process of a phenomenological analysis. Qualitative analysis is often described in a linear fashion - moving forward through the data. IPA analysis is not linear (Smith, Flowers, \& Larkin, 2009) and, as such, it is worth highlighting the recursive nature of IPA analysis.

\subsubsection{Idiography}

Idiography, a concern with the particular, has been a major influence on IPA. This concern manifests at two levels. First, IPA is committed to in-depth and detailed analysis of the phenomena on which it is focused. Second, IPA is concerned with how experiential phenomena are understood from particular perspectives. Hence the effective use of single case analysis and the commitment to the single case in its own right. This idiographic focus on the particular is 'in contrast to most psychology which is 'nomothetic' and concerned with making claims at the group or population level, and with establishing general laws of human behaviour' (Smith, Flowers, \& Larkin, 2009, p.29).

The goal with IPA is thus not generalisable knowledge; the goal is transferable knowledge.

\section{Method}

\subsection{Research question}

With a particular focus on stress, coping and recovery, what is the lived experience of TBI?

\subsection{Participant}

The study recruited the participant, 'P', from existing professional networks. In order to ensure anonymity, the authors report only general participant details. $\mathrm{P}$ is a married man, in his forties. He is a father of three teenage children, who works fulltime in a professional capacity. Two years prior to the interview, the participant suffered a severe, lifethreatening TBI following a high-speed bicycle fall while participating in a race. $\mathrm{P}$ was wearing a helmet at the time, but still sustained a serious injury to his left frontal lobe. To convey a sense of the injury in his own words P reported:

'I was coming down xxx pass from the car park towards xxx going fast, because it's downhill. Erm, nobody knows what happened because nobody saw what happened. I don't remember anything happening but I came off my bike erm who knows how, and hit my head. There is speculation that I may have hit it against the wall because the wall is very close to the side of the road there. Like only a foot or so away from the wall. So if you do go over the handlebars for whatever reason, there is a good chance that you are going to hit the wall. Erm so I ended up cutting my head. So I actually had a wound, It was more than just a wound, or a bang in the head. It was actually cut open as well. So I hit something sharp. Erm, in the process and then must have skidded on my side quite a long way because the whole of my right hand side was grazed. Erm, yeah and some walkers got to me. They heard it. They heard me crash, and they got to me and they basically held me together. They basically held my head together...

So what had happened is that I'd basically, I'd, it was a complete, I dunno what you call it, whole piece of skull. It was a depressed fracture. So a whole piece of skull had snapped. About the size of a saucer I suppose. A tea cup saucer, a whole piece of skull had been broken and then pushed into my brain. And the eye socket had hinged and apparently there's some sharp bits at the back of your eye socket and that had sort of, one of those had gone up because it had hinged. It had gone up. Punctured the membrane. Gone into my brain. Erm and there was bleeding on the brain.

So it was a severe injury and basically the walkers got to me and sort of kept me together. From what I've heard, I understand there was an ambulance at the top, or not too far away anyway and the ambulance was called. I think that the second person on the scene was a nurse and then they got the road ambulance. The road ambulance basically stabilised me. Got me to $\mathrm{xxx}$ hospital. $\mathrm{xxx}$ hospital then took one look at me and said we're not touching you. And then I got airlifted to Yyy which is the head trauma centre. Erm, they cleaned me out on that Saturday and they did the big op on the Tuesday'.

\subsection{Interview}

The interview process took place on University premises and lasted for approximately one hour during which the participant $(\mathrm{P})$ read an information 
sheet, completed a consent form, and had the opportunity to ask questions about the research at hand.

\subsection{Transcription}

The interview was recorded on an audio device and transcribed immediately afterwards by the interviewer (SW).

\subsection{Analysis}

IPA analysis is an iterative, recursive process. As such, we felt that it makes sense, adds coherence, and renders our analysis more transparent, to report, and discuss, our results in a manner that mirrors that in which we produced them. Smith, Flowers and Larkin (2009) make clear that there is no 'right' way to do IPA. One advantage of the manner in which we present our results in this paper, in combination with method and discussion, is that it makes our sensemaking of the participant's sense-making transparent. This double hermeneutic is absolutely fundamental to IPA and, in our opinion, it emphasises the golden thread of narrative that runs throughout our report uncertainty is at the heart of the lived experience of TBI.

IPA analysis was conducted in the manner suggested by Smith, Flowers and Larkin (2009): 1. Reading and re-reading; 2. Initial noting; 3. Developing emergent themes; 4 . Searching for connections across emergent themes. In order to break the narrative flow and deconstruct the transcript we utilised a suggestion that Smith et al offer and worked through the transcript backwards, paragraph by paragraph, as well as reading from start to finish in the usual manner.

After working on initial coding of the transcript the first author passed on a synopsis of initial codes to the remaining authors for their input. These initial codes were accompanied by the transcript, as annotated by the first author.

Linguistic comments; comments pertaining to concepts; and descriptive comments (i.e. pertaining to meaning and concerns). All of the co-authors discussed and agreed initial coding at this stage. The initial codes are outlined below.

\subsection{Linguistic comments}

There was interesting movement between the active voice and the passive voice, between engaged and detached, and between first person and third person.

Examples:

In the opening part of the interview, $\mathrm{P}$ talks about a whole piece of skull snapping and 'it was a severe injury'. He doesn't say 'I had' but rather 'it was'. This reflects his experience. In describing the injury he begins from a position of detachment.

Similarly, a little later, $\mathrm{P}$ says: 'So obviously, my brain had already processed that there was something going on'.

This seems a rather distanced way for $\mathrm{P}$ to speak of himself. Slightly jarring.

The language used during the interview serves to position $\mathrm{P}$ as passive. 'I ended up in $\mathrm{xxx}$ '

However, there is a shift in gear after about $5 \mathrm{~min}$ utes into the interview when P says: 'I had a serious confabulation'.

Not 'my brain had' or 'the injury rendered me confused' but 'I had'. It's interesting that the next sentence evidences concern with using the correct terminology. Is this about validating his experience? It later transpires that $\mathrm{P}$ has had previous mental health issues. Is the change of gear because he is on 'safer ground' talking about mental health than TBI?

It is notable that, excepting on one occasion, the language $P$ used for family members might be read as rather distant and does not use any names. 'My wife', 'she,' 'they,' 'the kids,' 'my mother,' are the order of the day. It may be that this language is indicative of distance, or detachment.

A line that jumped off the page at us on first reading the transcript is where $\mathrm{P}$ says that he latches on to 'an idea then peck people's heads about it'. This is a most vivid use of language and it serves to position $\mathrm{P}$ as both engaged, and as an outsider poking in. It is reminiscent of Socrates and the gadfly. Perhaps we are reading too much into this line, but it does convey a somewhat ominous feeling of discomfort to the reader.

When linking his experience of TBI to his depression, $\mathrm{P}$ takes possession of the narrative:

'I equate (TBI) as very similar to my experiences with depression'.

It may be that the same thing is at play here as in the section mentioned earlier where there was the shift in gear to 'I'.

As the interview proceeds we move back to the more passive version of $P$.

'My personality is quite project-focused'.

Not 'I am .... ., instead, $\mathrm{P}$ is quoting himself. He is very much in the observer role here and it conveys 
an impression of unemotional detachment from the thoughts described. Almost cold.

'I'm not going to let this little brain injury thing stop me...'.

$P$ refers to his marriage as 'the relationship'.

Not 'my relationship'/'my marriage' etc. Again, this might be perceived as detachment. Also, there is evidence of loss (on the family's part) behind the way language was deployed here.

As the interview approaches the half-way point we have another shift of gear back to 'I'. This shift was prompted by the question about uncertainty and we think it is because the device of 'project focus' is being used to position $\mathrm{P}$ as having some element of control over his life and circumstances.

'I can keep going a bit more'.

It seems that positioning and control is also behind P's description of what was a life- threatening and life-altering TBI as a 'serious bump on the head'.

\subsection{Concepts}

There were some fascinating concepts in this transcript.

The first concept we picked out was the concept of project and project focus. For example, P says that 'I see my life in terms of projects'.

Across the entirety of this interview, uncertainty loomed large and it is interesting how the concepts of the project and uncertainty are almost oppositional, or counterbalancing, in terms of each other. The impression we derived from the transcript is of finely balanced coping:

"It may be a bounce back reaction and it's like I'm on my second life now so I' $m$ just going to go for it. But there is that niggling idea that I've damaged my brain. Whether that's noticeable on a day to day level and whether that has any effect on any future deterioration of any sort. I don't know. But there's part of me that goes ... It just give you that sense of mortality and it's like I don't know how much longer I've got with a fully functioning mental capacity. So you kind of have a project and this is like what I want to achieve now because its, I don't know, just in terms of work, it's like thinking through to retirement at 65 is like I don't know if I have that long left. That might be something that everyone thinks at my age, or not, I don't know. But from my perspective it's like I don't know how many good years I've got'.
A second concept that we identified in the transcript is the link to depression. At several points, $\mathrm{P}$ links his previous experience of depression with his current experience of TBI:

"But then I see it's (i.e. the TBI) very similar as to when I was diagnosed with the depression. People start or at least it feels like they start treating me differently because they now see you as a medical case and in both of these I've always argued, it's like stop medicalising me".

"And it feels the same with my depression".

There is also a conceptualisation of the person that is both social and personal. There is, on the one hand, a thread invoking an almost unconscious need for recognition of context, and a holistic view of P's being in the world, running through the entire transcript. On the other hand, there is a view that $\mathrm{P}$ is very much an individual. It seems that this was evident to $\mathrm{P}$ who felt the need to express it explicitly at the end of the interview:

"Another thing I want to say is that the whole person-centred element is quite erm current. And you know you get quite person-centred learning and person-centred counselling. So just from my experience the whole person-centred approach to dealing with brain injury and listening to their experience. What I struggle with medically is that the medical system focuses on the patient and it is all about the patient and patient care. And fails to see a more holistic view in terms of the family and the kids. So if I go to the doctor and say I've had a brain injury, they'll say 'ok' and I'll deal with you and they may listen to you. But the family and the kids, they're their own problem. Not part of the solution and the listening process".

Perceptions and differences in perceptions figured prominently in the interview: $\mathrm{P}$ sees his injury as a predominantly physical thing. For his family, it's a psychological event. $\mathrm{P}$ is blasé about it whereas for his family it is traumatic. For $\mathrm{P}$ it is a progression, and for his family it is a triggering event:

"I see it more as a progression thing rather than a purely post injury before and after because I see there were things happening in my life, in me and my relationship prior to the accident. Whereas I think they tend to see it, they have the accident very much as a, an event that triggered things. Whereas I see there was an event, and it may have 
triggered things, changed things, but it may have just accelerated what was already happening and I see it within a much longer time frame".

There is also a divergence of perspectives: For the family the injury was a shared, traumatic experience. Whereas for $\mathrm{P}$ it is experienced as a distant event:

"I'm sort of distant from it in a way because they don't talk to me that much and when I try to ask them then there seems to be this conflict about what they say they're thinking and what my wife says is reporting to me what they're thinking. It's just a big muddy".

Then there are the differences with regard to P's immediate family and those one step removed who see his as a miraculous recovery:

"There's a bit of conflict between her and my family because my mum is like 'oh what a miraculous recovery,' you know, we're all so pleased and Mary (pseudonym) is like 'You should try living with him'. (Both Laugh). It's not all roses. So that has led to a bit of a fall out as well. Because its perspective and how close. Anyone who is like one step removed from me seems to think like I'm fine".

\subsection{Descriptive comments (meanings and concerns)}

The TBI has some overlap with P's experience of depression in terms of what it means to him. But the different use of language around each suggests that the depression has been processed in a way that the TBI has not. For example, $\mathrm{P}$ tended to use the first person when speaking about his depression and the third person when speaking about his TBI. Is it that the depression is experienced as resolved?

\subsubsection{Uncertainty}

A couple of years after his accident, $\mathrm{P}$ returned to compete in, and complete, the event in which he had suffered the TBI. It may be that P's return to the event where he almost died means significantly more to him than the mere 'box to be ticked' that he talked about in the interview, or a consequence of 'project focus'. P's description of the event he was taking part in at the time of his injury as 'The bruiser' is, perhaps, telling. We think that P's description of the accident as a physical event for him but as a psychologically traumatic one for his family is also telling. The accident means different things to different people. There is considerable uncertainty attaching to it. There seemed, to us, to be scant overt emotion attaching to the TBI from P's perspective. However, we could not help but wonder, on reading the transcript, whether the repetition of the event may not have had something to do with a desire to resolve and reduce uncertainty. Even if this processing was taking place outside of conscious awareness.

Lastly, there seems to be something pertaining to both meaning and concern in that $\mathrm{P}$ experiences his TBI as an event falling on the continuum of his life:

'I always used to describe myself, before I was depressed, as the man who shrugs. I used to just shrug stuff off and I didn't have any strong feelings or care. It was like if you want to do that, that's fine. I'm not bothered. And since the depression and maybe even more now, I've kind of felt like I am standing up more for myself and how that comes across is probably just rude and aggressive (laughs). Particularly if that is in contrast to how I was 15 years ago or whatever. Then it is suddenly like, you're being a bit aggressive here. Being a bit selfish and a bit self-centred and all the rest. Whereas to me it is simply like I am trying to get my point across.'

Whereas for others in P's immediate family, the event is like a light switch moment. It is clear that there is loss implied in his family's experience. It is less clear whether $\mathrm{P}$ is sharing that experience of loss at an emotional level.

Another very important aspect is that $\mathrm{P}$ is still 'a valid human being'.

For P: "one particular stress (is) around the sort of long term effects and changes, I equate as very similar to my experiences with depression. Erm, in that two things. One is that my kind of denial and inability to see how I've changed. It's clear that my wife and she reports some of our friends, see that I behave differently. And that I am somehow quite different. And that's not seen with my work colleagues. So it is only people who are close and sort of live with me or have experienced me closely see those changes that maybe even I don't see. Some of them I can accept on a kind of intellectual level. But I don't see that I am radically different now as I was then. Because that's a conflict, I think that's quite stressful. But then I see it's very similar as to when I was diagnosed with the depression. People start or at least it feels like they start treating me differently because they now see you as a medical case and in both of these I've always 
argued, it's like stop medicalising me. You're treating me like I' $m$ a case book and I just find that really stresses me. I'm still a person. I'm still a valid human being. It feels like other people are always interpreting you and analysing you through that perspective of 'you've got a brain injury' or 'you've behaved differently' or 'your personality has changed' or whatever it is. And it feels like you are no longer being taken at face value".

\section{Themes and discussion}

IPA begins with, but should go beyond, a standard thematic analysis (Brocki \& Wearden, 2006). Following initial coding, we identified four themes. In line with the guidance offered by Braun and Clarke (2006), these themes were produced/arrived by organising those codes that had been identified in the first stage of analysis into bigger patterns of meaning that spoke directly to our research question. We also tried to take on board the advice of Smith and Osborne (2003, p.71) to imagine a magnet with some of the themes pulling others in and helping to make sense of them.

As the analysis proceeded recursively in steps, developing emergent themes and searching for connections across emergent themes merged, producing connected themes: 1 . Paradox/contradiction; 2 . Shifting perspectives/discontinuity; 3. Self under stress. Uncertainty was an overarching theme.

In order to keep on the phenomenological track, the four aspects of life-world (temporality [experience of time], spatiality [experience of space], embodiment [experience of being in a body], and inter-subjectivity [the relational aspect of lived experience]) guided the authors. These acted as focal points during theme exploration. It is also necessary to state that, in line with the IPA guidance offered by Smith, Flowers, and Larkin (2009), theme construction primarily derived from coding notes. The purpose of conducting analysis in this way was to facilitate breaking up of transcript narrative flow. This represents a manifestation of the hermeneutic circle, where the themes identified capture and reflect understanding (Smith, Flowers, \& Larkin, 2009).

\subsection{Paradox}

The 'paradox' theme is important. Before coming to the specifics of the case at hand, it is worth noting that one significant, and generally unconsidered, paradox is that the experience of TBI is simultaneously intensely individual and intensely social (Walsh, Fortune, Gallagher, \& Muldoon, 2014). Historically, approaches to brain injury rehabilitation have been rooted in individualism. These individualistic ways of understanding TBI were, and remain, important. However, individual selves can also be understood as reflective of social constructs which arise from social contexts. Hence, it is useful to view TBI as having a social aspect.

The social and individualistic frames for understanding TBI are not 'either/or'. Yes, it is paradoxical that TBI is both individual and social. However, Bowen, Yeates and Palmer (2010) propose that in order to understand fully what lies within the brain, neuropsychological inquiry must look outwards to social relations and context.

Furthermore, it has not escaped our notice that there is also a contradiction in our using a single case study to explore 'the social'.

In considering the lived experience of $\mathrm{P}$, we find much that is paradoxical. For example, $\mathrm{P}$ is both detached (e.g., 'Erm, so yeah. I'm sort of distant from it in a way because they don't talk to me that much and when I try to ask them then there seems to be this conflict about what they say they're thinking and what my wife says is reporting to me what they're thinking'.) and engaged (e.g., 'I latch onto an idea then peck peoples heads about it'); active (e.g. 'I'm quite project focused. And I think I have become more so since the injury') and passive (e.g., 'So obviously, my brain had already processed that there was something going on'; 'my personality is quite project focused'); individual and social (explored further in 'self under threat' theme); ABI is seen as both a continuum with the past (e.g., 'I always used to describe myself, before I was depressed, as the man who shrugs. I used to just shrug stuff off and I didn't have any strong feelings or care. It was like if you want to do that, that's fine. I'm not bothered. And since the depression, and maybe even more now, I've kind of felt like I am standing up more for myself and how that comes across is probably just rude and aggressive (laughs). Particularly if that is in contrast to how I was 15 years ago or whatever. Then it is suddenly, like, you're being a bit aggressive here. Being a bit selfish and a bit self-centred and all the rest. Whereas to me it is simply like I am trying to get my point across.') and as a break with the past (e.g., 'And this is probably where it is a sticking point, I see it more as a progression thing rather than a purely post injury before and after because I see there were things happening in my 
life, in me and my relationship prior to the accident. Whereas I think they tend to see it, they have the accident very much as a, an event that triggered things. Whereas I see there was an event, and it may have triggered things, changed things, but it may have just accelerated what was already happening and I see it within a much longer time frame').

Platt (2001) discusses the use of paradox in Shakespeare and argues that a recognition of the paradoxical nature of the world is a prerequisite for cognitive growth. According to Platt, this applies to both characters and audience (intrinsically social and individual!). We argue that Shakespeare, perhaps the shrewdest observer of human nature to ever write in the English language, picked up on something that we, as psychologists focused on rehabilitation, can usefully apply to thinking about rehabilitation following brain injury - the idea that paradox needs to be recognised in order for a person to move forward and grow post TBI.

Vygotsky (1978) offers an extraordinarily useful set of thinking tools to contemporary psychologists wishing to grapple with what appears to be paradox. Cole and Scribner (1978, p.6-7) report that 'Vygotsky saw in the methods and principles of dialectical materialism a solution to key scientific paradoxes facing his contemporaries'. A central tenet of this method is that phenomena should be studied and understood as processes in motion, and in change. Thus, when Vygotsky speaks of his approach as "developmental" this is not to be confused with a theory of child development. The developmental method, in Vygotsky's view, is 'the central method of psychological science'. The dialectic represents opposing directions of thought united in a continuous whole. This way of approaching paradox in a holistic manner allows us to transcend binary thinking and, in Vygotsky's view, should facilitate an enhanced understanding of the human psyche (Daniels, 2008).

As one of the research team (DF) was examining the transcript for the first time, that hoary old 'two roads diverged in a yellow wood' came to their mind. A question arose as to whether P's narrative represented a 'real' (i.e. as others might consider it) or interpersonal/intrapersonal divergence. In the specific case of $P$, and the broader context of TBI cases generally, these questions are there to be thought through. On discussion, amongst the authors, the diverging road image spoke to the image of a ' $\mathrm{Y}$ '.

One group of researchers who have spent considerable time on precisely this aspect of TBI, in terms of a ' $\mathrm{Y}$ ' shaped model of the rehabilitation process, are Wilson, Gracey, Evans, and Bateman (2009). Pictured as a ' $Y$ ' the top left of the ' $Y$ ' is seen as pre-injury self-representations, and the top right of the ' $\mathrm{Y}$ ' is seen as the self in current context. The gap between both is the experience of self under threat. Alternatively, discrepancy. Hence, the model fits easily with both Vygotskian understanding of lifespan development as process, and the Allostatic brain literature which regards stress (in this case ABI) as a generator of existential uncertainty.

It is noteworthy that TBI survivors often seem cognitively intact to interviewers (and others) and that the person with TBI does not perceive changes in themselves in the same manner that their family members do (Newby, Coetzer, Daisley, \& Weatherhead, 2013). This is discussed further below. Rehabilitation, according to Wilson, Gracey, Evans, and Bateman (2009) is about bringing the discrepant arms of the ' $\mathrm{Y}$ ' in the survivor's rehabilitation process together as TBI survivors integrate their pre- and postinjury selves, as well as those around them, and the world in general.

It is a paradox that $\mathrm{P}$ is both the same but different, and the reasons are both individual and social. Under the spotlight of TBI, the consequence of this unresolvable paradox is uncertainty.

Newby, Coetzer, Daisley, \& Weatherhead (2013) report that disinhibition and social isolation are common following TBI. Moreover, because survivors often do not experience the same changes as those around them, others do not perceive that they require rehabilitation. This discerned continuity, as evidenced by $\mathrm{P}$ in this report, as well as the perception of disinhibition on the part of the family, may reflect an attempt to mitigate uncertainty. This process is thus best understood holistically. Research has shown that individuals experience greater change during times of uncertainty, and when stress is high (Tedeschi \& Calhoun, 1996).

The uncertainty and stress literature (e.g., Peters, McEwan, \& Friston, 2017) outlines how, in contexts where uncertainty remains unresolved, individuals encounter allostatic load. Habituation is key to wellbeing for those faced with long-term exposure to allostatic load. Probability appraisal, in turn, is key to habituation. Those who habituate do so by broadening their probability expectations of goal states divergence (Peters, McEwan, \& Friston, 2017). In other words, people predict that they will often be wrong in their predictions. They become reconciled with uncertainty. 
Conclusion - Paradox: The certainty of uncertainty relieves uncertainty.

\subsection{Shifting perspectives}

Perspective-taking is about seeing, and appreciating, things as others do. Perspective-taking is purposeful. Attempting to walk in another's shoes, so to speak. Things that one can take a perspective on include situations, states, and objects (Echterhoff \& Higgins, 2011). One reason that we take perspectives is to understand others and predict their behaviour. As outlined earlier in the paper, allostatic load, related to uncertainty, feeds into chronically activated stress responses.

In P's narrative, perspective-shifting attempts are apparent throughout. $\mathrm{P}$ is concerned with how others see him, he shifts between 1st and 3rd person when referring to himself. Considered from an allostatic load framework, TBI generates a tsunami of uncertainty and delivers a double hit because: a) TBI constitutes an existential threat to the survivor, and those around them, and is thus both an acute and chronic source of uncertainty; b) An important purpose of our brains is to come up with strategies that reduce uncertainty. TBI impacts the organ's capacity to do this. Crucially it also impacts on the capacity to draw on social resources that might aid in uncertainty reduction via social support.

One way that TBI can influence the capacity to draw on social resources is via damage to those regions of the brain that impact a person's capacity to mentalise effectively (i.e. decode the mental states of others; Bowen, Yeates, \& Palmer, 2010). We perceived, perhaps mistakenly, some lack of capacity to appreciate the perspective of those close to $\mathrm{P}$, associated with comments where $P$ expressed frustration with being regarded as a 'medical case' and 'different'.

$\mathrm{P}$ also referenced his experience of cognitivebehavioural therapy (CBT) from his pre-TBI depression: "when I had my depression, I did a CBT course which is supposed to help. I maybe didn't take it as seriously as I could but there were elements of it that were useful at the time. But my wife says that I became much more aggressive as a result of it. Now I think we also have friends who did couples counselling prior to that and that was all about erm one of them being more assertive and I think she frames my CBT course in the same frame as their couples counselling and she has in her head that I was supposed to come back from the CBT more assertive and says I was more aggressive. That wasn't what the CBT was about but that is how she was interpreting".

This lead us to a consideration of how engagement with a formal therapy prior to a brain injury may influence the reaction and coping with a lifethreatening event, i.e. the brain injury itself. There was some blunting of affect discernible in the transcript which could be attributed to the TBI and/or perhaps the influence of a pre-TBI depression; $\mathrm{P}$ presented awareness of 'doing' as a coping mechanism however the 'feeling' was not as apparent. It is noticeable that $\mathrm{P}$ refers to the depression as 'my depression' which implies an ownership or internalization of it and he also acknowledged that there were aspects of the CBT which he found useful during that time. It could be that the CBT provided an alternative explanation from the medical model and therefore the 'label' under the psychiatric classification system could be challenged and under his control. $\mathrm{P}$ also referenced throughout the script his action-oriented personality and there could be a link with action-orientation and the implementation of behavioural activation strategies that are prevalent in CBT as a response mechanism. The use of actions can give a sense of control, particularly when someone is coping with dys-executive changes brought about by a brain injury (Evans, Emslie, \& Wilson, 1998). There is less evidence in the script of application of the CBT cognitive skill strategies to the TBI. The TBI itself is presented in a more medical light through the linguistic presentation of how it occurred and its impact. Another possible reason for presenting the TBI in a medical light may be that the CBT became a stressor as the perceived external reaction to it (from his wife) was one of reproach and therefore, altering cognitive and, in turn, communication style, may have been consciously avoided. $\mathrm{P}$ also highlighted in his own words a common criticism in the literature of the CBT approach in that in some cases it may become overly focused on formulations at the individual level of experience (Gaudiano, 2008) and that it made him consider a more 'holistic' approach in terms of addressing relationship issues-i.e. that therapy would include significant others in the context of a systemic approach.

A person's capacity to navigate their social world is compromised by TBI because it upsets delicate social ecosystems in subtle ways (e.g. Newby, Coetzer, Daisley, \& Weatherhead, 2013). We can see this in P's transcript, for example, in a section where he says that, following the TBI, 'I felt that I was fine 
apart from the tiredness. My wife says that I have changed and that I was a lot different. She says that I, kids have noticed differences as well. When I talk to my kids, they say that it is not that different. My wife is saying that it is more different than they have said. But there's a whole different perspectives thing going on'. We can see that, in line with the observation made by Newby et al, the TBI is a manifest source of uncertainty.

On the descriptive side, it seems that there is the appearance of some emotional detachment and the almost clinical description of the TBI event as if from a third party perspective. Might the engagement with therapy pre-TBI have influenced current coping style? Or is there a worry that if the emotions are experienced, then the depression may re-emerge? It does come across as being more part of a narrative than a specific event and there is a sense of almost annoyance at other's reactions. On considering the transcripts, we were drawn to the coping responses; doing the projects (e.g. "my personality is quite project focused") yet we also made reference to retreating (I think we've both kind of retreated to our safe spaces, which is not interactive); we can see that $\mathrm{P}$ seems to be engaging with the practical - but not the interpersonal.

It is often the case that people close to TBI survivors experience changes that the survivor does not. It is also clear that there are biological, psychological, and social aspects to the complex emotions (on all sides) associated with TBI (Newby, Coetzer, Daisley, \& Weatherhead, 2013).

In order to most effectively address allostatic load, in a rehabilitation context, we argue that the clinical focus needs to be on relational approaches (i.e. as per Bowen, Yeates, \& Palmer, 2010). Social context and relationships are therefore vital. We need to ensure that the capacity for shifting perspectives is as functional as possible.

\subsection{Self under stress}

It is clear from the transcript that $\mathrm{P}$ embodies a self under stress. This is not at all unusual in the context of TBI.

At this point, it is important and necessary to outline exactly what we mean when using the word 'self'. In the contemporary neuropsychological rehabilitation literature ideas of personality have been superseded by concepts of cognitive representations of 'self' (Yeates, Gracey, \& Collicutt McGrath, 2008). Within the social identity approach, Simon
(2004, p.9) suggests that multiple possible identities emerge from interaction between individual brains and their environments. Simon (2004) deploys the idea of identity in a broad sense to cover phenomena, and processes, discussed by others under the heading 'self' (Simon, 2004, p.2). We have followed Simon's lead with regard to defining 'self' and 'identity' in this paper.

So, identity can be understood as the product of self-interpretation processes which take place as the result of social interaction (Simon, 2004). Hence we are dealing with what might be regarded as a dialectic (or paradox) where one pole of the concept of self is social, and the other is individual.

Social identities are those selves, based on valued group memberships, that constitute who, as individuals, it is that each of us understand ourselves to be. At our base, each of us has social identities, selves, that are relational and founded upon relationships.

Walsh, Fortune, Gallagher, and Muldoon (2014) argue that in order for identities to be viable following TBI, survivors must be able to perform their identities. It may be that this performative aspect of identity was the driver of P's re-participation in a race that had almost killed him on his previous attempt. Hogg (2016) discusses social identity in the context of existential threat and it is relevant that the idea of social identity itself, and social identity as a body of theory, was born out of existential threat in the theory founder's own life ${ }^{1}$.

Following TBI, the neuropsychological rehabilitation literature "consistently shows that TBI devastates relationships of all kinds" (Newby, Coetzer, Daisley, $\&$ Weatherhead, 2013, p.272.). Hence, according to Newby et al. (p.123) identities (or self-constructs) are rendered fragile and left threatened by TBI.

Threatened identity is linked to the experience of uncertainty and people are motivated to reduce uncertainty (Hogg, 2016). Furthermore, as outlined earlier in this paper, uncertainty is intrinsic to the experience of allostatic load. It may well be that the experience of uncertainty ties into P's projects (e.g. "I see my life in terms of projects. The whole doing the same event (after the injury) was a project. It was a big project, and I was just very focused on that. It wasn't a catharsis thing. I didn't do it because it, because I had to do it, it was because previously it was on my

\footnotetext{
${ }^{1}$ The founder of Social Identity Theory, Henri Tajfel, was a Polish Jew who survived imprisonment by the Nazis as a consequence of hiding his Jewish identity.
} 
tick list") and in terms of psychology, factors relating to efficacy (e.g. Bandura, 1995).

Hogg (2016, p.10) suggests that social categorisation is 'particularly effective at reducing uncertainty because it furnishes group prototypes that describe how people (including self) will and ought to behave and interact with each other'. To a significant degree, being able to competently self-categorise reduces uncertainty because the groups that we belong to prescribe our behaviour when acting as members of those groups. Conceptually, this is very close to the metaphoric identity mapping (e.g. Ylvisaker et al., 2008) with which many of us are more familiar.

Indeed, it may well be that there is utility in assessing social categorisation skills in order to reduce uncertainty for those living with TBI (based on Hogg, 2016).

Ontologically, human beings are social creatures (e.g. Daniels, Cole, \& Wertsch, 2007) and most usefully in terms of TBI rehabilitation, according to Simon (2004), people are most usefully understood in terms of process, rather than essence. Relatedly, we need to think in terms of people rather than brains - people have relationships with other people, brains don't. This point manifests powerfully in the current paper when $\mathrm{P}$ talks about himself not being a medical case and still being a 'valid human being':

"So one particular stress around the sort of long term effects and changes, I equate as very similar to my experiences with depression. Erm, in that 2 things. One is that my kind of denial and inability to see how I've changed. It's clear that my wife, and she reports some of our friends, see that I behave differently. And that I am somehow quite different. And that's not seen with my work colleagues. So it is only people who are close and sort of live with me or have experienced me closely see those changes that maybe even I don't see. Some of them I can accept on a kind of intellectual level. But I don't see that I am radically different now as I was then. Because that's a conflict, I think that's quite stressful. But then I see it's very similar as to when I was diagnosed with the depression. People start, or at least it feels like they start, treating me differently because they now see you as a medical case and in both of these I've always argued, it's like 'stop medicalising me.' You're treating me like I' $m$ a case book and I just find that really stresses me. I'm still a person. I'm still a valid human being. It feels like other people are always interpreting you and analysing you through that perspective of 'you've got a brain injury' or 'you've behaved differently' or 'your personality has changed' or whatever it is. And it feels like you are no longer being taken at face value".

This tension between being a 'valid human being' and being a 'medical case' also shows that, as well as being exceedingly uncertain, the internalised perspectives and judgements of others have a huge voice in P's experience. This tension is adding to the uncertainty that is hovering with regard to physical and psychological integrity, mortality, and the myriad other issues facing $\mathrm{P}$.

We know from the literature that a person's adjustment to life post TBI is dynamic. As such, relationships are important and, we argue, in thinking about adjustment, we need to adopt a relational approach. A relational approach that commences with the survivor's relationship with himself or herself (Newby, Coetzer, Daisley. \& Weatherhead, 2013).

$\mathrm{P}$ describes his experience of TBI as akin to his diagnosis with depression. $\mathrm{P}$ perceives that people are treating him differently because he's a 'medical case'. Again, this experience conveys the impression of threat and uncertainty.

Luders, Jonas, Fritsche, \& Agroskin (2016) report that social exclusion has been found to increase aggressive behaviour. We get the sense from the transcript that, probably unintentionally, $\mathrm{P}$ feels that he has been, to some degree, marginalised. Luders et al. (2016) argue that even in unfavourable situations, highlighting potential benefits, and highlighting different ways of appraising the threat might change the perceived nature of threat and thereby help prevent negative outcomes. In other recent research, Greenaway et al. (2014) report that reminding people that they have some control over potentially threatening events eliminated threat effects.

\section{Conclusion}

The key goal of this report is not to generate generalisable knowledge. Rather, the intent was (is) to develop transferable knowledge that might be usefully applied in both clinical and research contexts.

There are many moving parts evident to those focused on a consideration of the lived experience of individuals who have experienced TBI. Paradox, shifting perspectives and self under stress were all to 
the fore in the transcripts that were the basis for this study. The thread that bound these factors together was uncertainty.

In contemplating the apparent tension between a need to focus on the individual, and the social, in the context of rehabilitation following TBI, we were faced with a question as to where the line should be drawn between individual and social psychology. Our conclusion, and our argument, is that, rather than conceiving of the individual and social as binary opposites, rehabilitation should approach the individual and social as dialectic components of lived experience. A relational approach that considers the relationships a given person has, as well as the presence (or sometimes the absence) of significant others within rehabilitation, is required.

Furthermore, because of the prominence of uncertainty in the lived experience of $\mathrm{P}$, it is our conclusion that reducing uncertainty (allostasis) must be a key component of post-TBI rehabilitation. This last point in particular is crucial. Based on the evidence presented in this report, we suggest that key components in this endeavour are likely to be social identities and self-categorisations: both of the TBI survivor, and those around them.

\section{Conflict of interest}

None to report.

\section{References}

Baddeley, A. (1993). A theory of rehabilitation without a model of learning is a vehicle without an engine: A comment on Caramazza and Hillis. Neuropsychological Rehabilitation, 3, 235-244. doi.org/10.1080/09602019308401438

Bakewell, S. (2016). At the Existentialist Café: Freedom, Being, and Apricot Cocktails with Jean-Paul Sartre, Simone de Beauvoir, Albert Camus, Martin Heidegger, Maurice Merleau-Ponty and Others. Other Press, LLC.

Bandura, A. (Ed.). (1995). Self-efficacy in changing societies. Cambridge University Press. https://doi.org/10.1017/ CBO9780511527692

Bowen, C., Yeates, G., \& Palmer, S. (2010). A Relational Approach to Rehabilitation: Thinking about Relatinships after Brain Injury. London: Karnac Books.

Braun, V., \& Clarke, V. (2006). Using thematic analysis in psychology. Qualitative Research in Psychology, 3(2), 77-101. https://doi.org/10.1191/1478088706qp063oa

Brocki, J. M., \& Wearden, A. J. (2006). A critical evaluation of the use of interpretative phenomenological analysis (IPA) in health psychology. Psychology \& Health, 21(1), 87-108. https://doi.org/10.1080/14768320500230185
Cole, M., Levitin, K., \& Luria, A. (2010). The Autobiography of Alexander Luria. New Jersey: Lawrence Erlbaum Associates, Inc.

Cole, M., \& Scribner, S. (1978). Introduction. In Mind in Society (Vygotsky, L.,). Cambridge, MA: Harvard University Press.

Daniels, H. (2008). Vygotsky and Research. London, England: Routledge.

Daniels, H., Cole, M., \& Wertsch, J. V. (2007). The Cambridge companion to Vygotsky. Cambridge: Cambridge University Press.

Echterhoff, G., \& Higgins, E. T. (2011). How communication shapes memory: shared reality and implications for culture. In G. R. Semin \& G. Echterhoff (Eds.), Grounding Sociality: Neurons, Mind, and Culture (pp. 115-146). London, England: Psychology Press.

Evans, J. J., Emslie, H., \& Wilson, B. A. (1998). External cueing systems in the rehabilitation of executive impairments of action. Journal of the International Neuropsychological Society, 4(4), 399-408. https://doi.org/ $10.1017 / \mathrm{s} 1355617798003993$

Friston, K. (2010). The free-energy principle: a unified brain theory? Nature Reviews Neuroscience, 11, 127-138. doi.org/10.1038/nrn2787

Gaudiano, B. A. (2008). Cognitive Behavioural Therapies: Achievements and Challenges. Evidence Based Mental Health, 11, 5-7. doi.org/10.1136/ebmh.11.1.5

Greenaway, K. H., Louis, W. R., Hornsey, M. J., \& Jones, J. M. (2014). Perceived control qualifies the effects of threat on prejudice. British Journal of Social Psychology, 53(3), 422-442. doi:10.1111/bjso.12049

Greenaway, K. H., Haslam, S. A., Cruwys, T., Branscombe, N. R., Ysseldyk, R., \& Heldreth, C. (2015). From "we" to "me": Group identification enhances perceived personal control with consequences for health and well-being. Journal of Personality and Social Psychology, 109(1), 53-74. https://doi.org/10.1037/pspi0000019

Haslam, S. A. (2004). Psychology in organizations: The social identity approach (2nd ed.). London: Sage.

Haslam, C., Jetten, J., Cruwys, T., Dingle, G., \& Haslam, S. A. (2018). The new psychology of health: Unlocking the social cure. Routledge. doi.org/10.4324/9781315648569

Hogg, M. A. (2007). Uncertainty-identity theory. In M. P. Zanna (Ed.), Advances in experimental social psychology: Vol. 39. Advances in experimental social psychology, Vol. 39 (p. 69126). Elsevier Academic Press. https://doi.org/10.1016/S00652601(06)39002-8

Hogg, M. A. (2014). From uncertainty to extremism. Current Directions in Psychological Science, 23(5), 338-342. https://doi.org/10.1177/0963721414540168

Hogg, M. A. (2016). Social identity theory. In S. McKeown, R. Haji, \& N. Ferguson (Eds.), Peace psychology book series. Understanding peace and conflict through social identity theory: Contemporary global perspectives (p. 3-17). Springer International Publishing

Hoofien, D., Gilboa, A., Vakil, E., \& Donovick, P. J. (2001), Traumatic brain injury (TBI) 10-20 years later: A comprehensive outcome study of psychiatric symptomatology, cognitive abilities and psychosocial functioning. Brain Injury, 15, 189-209.

Langdridge, D. (2007). Phenomenological psychology: Theory, research and method. Pearson Education.

Lazarus, R. S., \& Folkman, S. (1984). Stress, appraisal, and coping. Springer publishing company. 
Lieberman, M. D. (2013). Social: Why Our Brains are Wired to Connect. New York, NY: Oxford University Press, USA.

Luders, A., Jonas, E., Fritsche, I., \& Agroskin, D. (2016). Between the lines of us and them: Identity Threat, anxious uncertainty and reactive in-group affirmation: How can antisocial outcomes be prevented? In S. McKeown, R. Haji, \& N. Ferguson (Eds.), Understanding Peace and Conflict Through Social Identity Theory: Contemporary Global Perspectives (pp. 33-54). Basingstoke, England: Springer.

Maas, A. I., Menon, D. K., Adelson, P. D., Andelic, N., Bell, M. J., Belli, A., ... \& Citerio, G. (2017). Traumatic brain injury: integrated approaches to improve prevention, clinical care, and research. The Lancet Neurology, 16(12), 987-1048.

MacPherson, S. E., \& Della Sala, S. (Eds.). (2019). Cases of Amnesia: Contributions to Understanding Memory and the Brain. Routledge. Chicago.

Muldoon, O. T., \& Lowe, R. D. (2012). Social identity, groups, and post-traumatic stress disorder. Political Psychology, 33(2), 259-273. https://doi.org/10.1111/j.1467-9221.2012.00874.X

Muldoon, O. T., Schmid, K., \& Downes, C. (2009). Abstract. Applied Psychology, 58, 129-145. doi.org/10.1111/j.14640597.2008.00385.X

McEwen, B. S. (1998). Protective and Damaging Effects of Stress Mediators. New England Journal of Medicine, 338, 171-179. doi.org/10.1056/NEJM199801153380307

Newby, G., Coetzer, R., Daisley, A., \& Weatherhead, S. (2013). Practical Neuropsychological rehabilitation in acquired brain injury: A guide for working clinicians. Karnac Books.

Peters, A., McEwen, B. S., \& Friston, K. (2017). Uncertainty and stress: Why it causes diseases and how it is mastered by the brain. Progress in Neurobiology, 156, 164-188. doi.org/10.1016/j.pneurobio.2017.05.004.\#

Platt, P. G. (2001). "The Meruailouse site": Shakespeare, Venice, and paradoxical stages*. Renaissance Quarterly, 54(1), 121154. https://doi.org/10.2307/1262222

Qureshi, K. L., Upthegrove, R., Toman, E., Sawlani, V., Davies, D. J., \& Belli, A. (2019). Post-traumatic stress disorder in UK civilians with traumatic brain injury: an observational study of TBI clinic attendees to estimate PTSD prevalence and its relationship with radiological markers of brain injury severity. $B M J$ Open, 9, e021675. doi.org/10.1136/bmjopen-2018-021675

Romero, L. M., Dickens, M. J., \& Cyr, N. E. (2009). The reactive scope model - A new model integrating homeostasis, allostasis, and stress. Hormones and Behavior, 55, 375-389. doi.org/10.1016/j.yhbeh.2008.12.009
Scholten, A. C., Haagsma, J. A., Cnoosen, M. C., Olff, M., van Beeck, E. F., \& Polinder, S. (2016). Prevalence and Risk Factor for Anxiety and Depressive Disorders after Traumatic Brain Injury: A Systematic Review. Journal of Neurotrauma, 33, 1969-1994. doi.org/10.1089/neu.2015.4252

Shallice, T (2019). The single case study of memory. In S.E MacPherson, \& S. \& Della Sala (Eds). Cases of Amnesia: Contributions to understanding memory and the brain. Routledge, Oxford pp. 1-15.

Simon, B. (2004). Identity in Modern Society A Social Psychological Perspective. Oxford: Blackwell.

Smith, J. A., Flowers, P., \& Larkin, M. (2009). Interpretative Phenomenological Analysis: Theory, Method and Research. Thousand Oaks, CA: SAGE.

Smith, J. A., \& Osborne, M. (2003). Interpretative phenomenological analysis. In J. A. Smith (Ed.), Qualitative psychology: A practical guide to research methods (pp. 51-80). SAGE.

Tajfel, H. (1974). Social identity and intergroup behaviour. Social Science Information, 13(2), 65-93. https://doi.org/ 10.1177/053901847401300204

Tedeschi, R. G. \& Calhoun, L. G. (1996). The Posttraumatic Growth Inventory: measuring the positive legacy of trauma. Journal of Traumatic Stress, 9, 455-471.

Vygotsky, L., Cole, M., \& Scribner, S. (1978). Introduction. In Mind in Society. Cambridge, MA: Harvard University Press.

Walsh, R. S., Fortune, D. G., Gallagher, S., \& Muldoon, O. T. (2014). Acquired brain injury: combining social psychological and neuropsychological perspectives. Health Psychology Review, 8, 458-472. doi.org/10.1080/17437199.2012.733914

Wilson, B. A., Gracey, F., Evans, J. J., \& Bateman, A. (2009). Neuropsychological rehabilitation: Theory, models, therapy and outcome. Cambridge University Press.

Yeates, G., Gracey, F., \& Collicutt McGrath, J. (2008). A biopsychosocial deconstruction of "personality change" following acquired brain injury. Neuropsychological Rehabilitation, 18(5/6), 566-589.

Ylvisaker, M., Mcpherson, K., Kayes, N., \& Pellett, E. (2008). Metaphoric identity mapping: Facilitating goal setting and engagement in rehabilitation after traumatic brain injury. Neuropsychological Rehabilitation, 18(5-6), 713-741. https://doi.org/10.1080/09602010802201832 